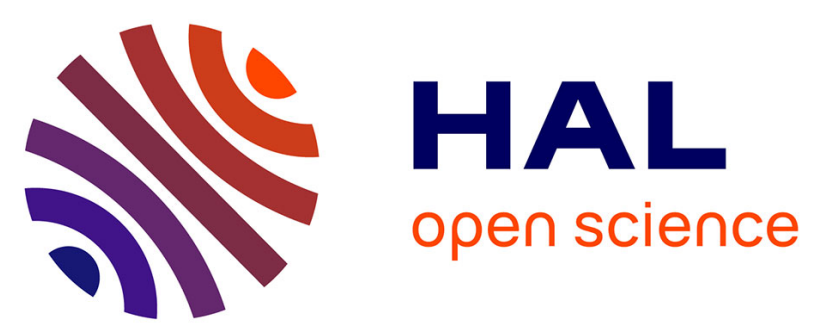

\title{
Stopped-Flow and DFT Studies of Proton Transfer and Isomerization of \\ 5-Amino-3-imino-1,2,6,7-tetracyano-3H-pyrrolizine and Its Related Base 2-(5-Amino-3,4-dicyano-2H-pyrrol-2- ylidene)-1,1,2-tricyanoethanide in Water: A Completely Sorted out Square Scheme
}

Edmond Collange, Alberto Flamini, Rinaldo Poli

\section{- To cite this version:}

Edmond Collange, Alberto Flamini, Rinaldo Poli. Stopped-Flow and DFT Studies of Proton Transfer and Isomerization of 5-Amino-3-imino-1,2,6,7-tetracyano-3H-pyrrolizine and Its Related Base 2-(5Amino-3,4-dicyano-2H-pyrrol-2-ylidene)-1,1,2-tricyanoethanide in Water: A Completely Sorted out Square Scheme. Journal of Physical Chemistry A, 2002, 106 (1), pp.200-208. 10.1021/jp011628e . hal-03294271

\author{
HAL Id: hal-03294271 \\ https://hal.science/hal-03294271
}

Submitted on 28 Jul 2021

HAL is a multi-disciplinary open access archive for the deposit and dissemination of scientific research documents, whether they are published or not. The documents may come from teaching and research institutions in France or abroad, or from public or private research centers.
L'archive ouverte pluridisciplinaire HAL, est destinée au dépôt et à la diffusion de documents scientifiques de niveau recherche, publiés ou non, émanant des établissements d'enseignement et de recherche français ou étrangers, des laboratoires publics ou privés. 
Stopped-Flow and DFT Studies of Proton Transfer and Isomerisation of

5-Amino-3-imino-1,2,6,7-tetracyano-3H-pyrrolizine and Its Related Base 2-

(5-Amino-3,4-dicyano-2H-pyrrol-2-ylidene)-1,1,2-tricyanoethanide in Water: a Completely Sorted Out Square Scheme

Edmond Collange, ${ }^{\mathrm{a}}$ Alberto Flamini ${ }^{\mathrm{b}}$ and Rinaldo Poli ${ }^{\mathrm{a}, *}$

${ }^{a}$ Laboratoire de Synthèse et d'Electrosynthèse Organométalliques, Faculté des Sciences

"Gabriel", Université de Bourgogne, 6 Boulevard Gabriel, 21000 Dijon, France

${ }^{\mathrm{b}}$ Istituto di Chimica dei Materiali del CNR, Area della Ricerca di Roma, P.O. Box 10, 00016

Monterotondo Stazione, Italy

${ }^{*}$ To whom correspondence should be adressed.

Tel: +33-3-80-39-68-81

Fax: +33-3-80-39-60-98

E-mail: Rinaldo.Poli@u-bourgogne.fr 


\begin{abstract}
A complete kinetic study of $\mathrm{pH}$-dependent isomerization of 5-amino-3-imino-1,2,6,7tetracyano-3H-pyrrolizine (HL) and 2-(5-amino-3,4-dicyano-2H-pyrrol-2-ylidene)-1,1,2tricyanoethanide $\left(\mathrm{L}^{\prime-}\right)$ in the $\mathrm{pH}$ range from -0.5 to 13 in aqueous solution, which spans over 7 order of magnitude for the pseudo-first order rates ( $\log k$ from -4.8 to 2.5 ) has revealed for the first time the existence of the corresponding conjugate species $\mathrm{L}^{-}$and $\mathrm{HL}^{\prime}$. The study has allowed the determination of the acid dissociation constants of HL $\left(\mathrm{p} K_{\mathrm{a}}\right)$ and $\mathrm{HL}^{\prime}\left(\mathrm{p} K_{\mathrm{a}}{ }^{\prime}\right)$, as well as all the individual forward and reverse isomerization rates of the acidic $\left(\mathrm{HL} / \mathrm{HL}^{\prime}\right)$ and basic $\left(\mathrm{L}^{-} / \mathrm{L}^{\prime-}\right)$ forms. While $\mathrm{L}^{\prime-}$ is the sole species present at $\mathrm{pH}>\mathrm{ca}$. 7, species HL and HL' establish an equilibrium favoring the former compound at low $\mathrm{pH}$, the distribution being ca. 79:21 at $\mathrm{pH}<$ ca. 2. A slow decomposition of HL occurs at low $\mathrm{pH}$ via the initial formation of an unobserved and unstable protonated form $\mathrm{H}_{2} \mathrm{~L}^{+}$. Geometry optimizations of all species at the B3LYP/LANL2DZ level, including water solvation energy, afford results in qualitative agreement with experiment and indicate the structural nature of the new species $\mathrm{L}^{-}$and $\mathrm{HL}^{\prime}$.
\end{abstract}




\section{Introduction}

The title pyrrolizine compound HL (see Chart 1)[Fares, 1995 \#4905] has attracted our attention because it is a species of prospective use in materials chemistry: it is a fluorescent dye, it can be sublimed to afford thickness-controlled thin films, and it coordinates to a number of transition metal cations.[Bonamico, 1989 \#4915; Bonamico, 1991 \#4906; Bonamico, 1992 \#4907; Bonamico, 1993 \#4908; Bonamico, 1993 \#4909; Flamini, 2000 \#4629] Like other similar conjugated heteropolycyclic molecules and their conjugate anions and complexes,[Preininger, 1996 \#5053; Mills, 1995 \#5054; Klein, 1994 \#5055; Wolfbeis, 1997 \#5056; Murkovic, 1997 \#5057; Plaschke, 1995 \#5058; Donckt, 1994 \#5059; Exstrom, 1995 \#5060; Daws, 1997 \#5061] it shows suitable properties for application in the construction of optochemical sensors.[Fares, 1998 \#4910; Panusa, 1996 \#4911; Flamini, 1999 \#4912] HL, whose bicyclic nature is shown by an Xray crystallographic study,[Fares, $1995 \# 4905]$ is prepared by protonation in water of the sodium salt of the anion $\mathrm{L}^{-}$(Chart 1), which derives from a reductive autocondensation of tetracyanoethylene.[Flamini, 1992 \#4913] The "open" form of the anion shown in Chart 1 has been evidenced by an X-ray structure of the tetraphenylarsonium salt.[Fares, 1995 \#4914] However, the anion rearranges to a "closed" bicyclic form also upon coordination to metal centers (see ML in Chart 1).

$<$ Chart $1>$

Prior to the present investigation, no information was available on the existence of a noncoordinated "closed" form of the anion, i.e. $\mathrm{L}^{-}$, and of an "open" form of the acid, HL', nor on 
the acid dissociation constants of HL and HL', nor on the rates and mechanisms of the opening and the reverse closing reactions on either the neutral molecule or the anion. These questions have been addressed in this study.

\section{Experimental Section}

Materials. Compounds $\mathrm{NaL}^{\prime} \cdot \mathrm{xH}_{2} \mathrm{O}$ and $\mathrm{HL}$ were synthesized according to the published procedures.[Flamini, 1992 \#4913; Fares, 1995 \#4905] Standard solutions of $\mathrm{NaOH}$ and $\mathrm{HCl}$ were obtained from Prolabo Normadoses. Buffers or buffer constituents (acids and conjugated bases) solutions were prepared from usual commercial products: sodium formate, formic acid, sodium acetate, acetic acid, sodium monochloroacetate, monochloroacetic acid, boric acid, hexamethylenetetramine, imidazole, hydroxylamine, histidine, sodium phosphate, sodium hydrogen phosphate, sodium dihydrogen phosphate, and sodium carbonate. Sodium chloride was used to adjust the ionic strength to 0.1 (with the exception of the very acidic or basic solutions).

Instrumentation. IR spectra were measured with a Perkin-Elmer 16F PC FT spectrometer, visible spectra were recorded on Varian Cary 5 and Cary 1 spectrophotometers. The stopped flow kinetic runs were carried out with a Hitech SF-61-DX2 apparatus coupled with a Hitech diodearray UV-visible spectrophotometer.

Kinetic measurements. (a) By stopped flow. Kinetic traces were recorded at $25^{\circ} \mathrm{C}$ in the $\mathrm{pH}$ range 2-12. The cell path length is $1 \mathrm{~cm}$. The $\mathrm{pH}$ values for the buffer solutions were determined with a Tacussel Minisis pHmeter, calibrated at $25^{\circ} \mathrm{C}$ with NBS standards. For the very acidic solutions $(\mathrm{pH}<1)$ the acidity function $\mathrm{H}_{0}$ is used in place of $\mathrm{pH}$.[Paul, 1957 \#5205] Two types of manipulations were carried out as follows. 
Type 1 experiments (from $\mathrm{HL}$ ). A $2.5 \cdot 10^{-3} \mathrm{M} \mathrm{HL}$ stock solution was prepared in acetonitrile, since this compound is only sparingly soluble in water. For each stopped-flow kinetics run, the HL solution was prepared by diluting this stock solution 1:50 (v/v) with $0.1 \mathrm{M}$ $\mathrm{HCl}\left([\mathrm{HL}]=5 \cdot 10^{-5} \mathrm{M}\right)$. This operation was carried out no more than $1 \mathrm{~min}$ prior to injection into the stopped-flow cell. Under these conditions, the advancement of the conversion reaction prior to injection $\left(k \approx 10^{-4} \mathrm{~s}^{-1}\right.$, see Results and Discussion) is negligible. The above solution was mixed in the stopped-flow cell with an equivalent volume of an aqueous solution containing $\mathrm{NaOH}$ (for the kinetic run at $\mathrm{pH} \geq 12$ ) or weak base $\mathrm{B}$ at appropriate concentration (thereby forming a $\mathrm{B} / \mathrm{BH}^{+}$buffer), for the kinetic runs in the $6-12 \mathrm{pH}$ region. The final proportion of organic solvent in the cell $(\approx 1 \%)$ is considered negligible.

Type 2 experiments (from $L^{\prime \prime}$ ). An approximately $5 \cdot 10^{-5} \mathrm{M}$ aqueous solution of $\mathrm{NaL}^{\prime}$ was mixed with an equivalent volume of either $\mathrm{HCl}$ solutions or with buffer solutions. The concentration of the starting $\mathrm{L}^{\prime}$ solution for type 2 experiments cannot be adjusted by weight, because the starting material $\mathrm{NaL}^{\prime} \mathrm{xH}_{2} \mathrm{O}$ has a variable amount of water. This does not represent a problem for the determination of the rate constants since all transformations follow first order rate expressions. Knowledge of the exact concentration, however, is necessary to analyze the equilibrium spectra. This knowledge was obtained as follows. Each stock solution of $\mathrm{NaL}^{\prime} \cdot \mathrm{xH}_{2} \mathrm{O}$ was used to record a spectrum in a $\mathrm{pH}$ ca. 7 buffer, where this remains the only species at equilibrium (see Results). This spectrum was compared with that obtained from a type 1 experiment in a $\mathrm{pH} 6.75$ buffer, where a solution of $\mathrm{HL}$ at a known concentration transforms quantitatively to $\mathrm{L}^{\prime}$.

(b) By mixing and monitoring. At $\mathrm{pH} \leq 2$, the evolution of the system is very slow $(k<$ ca. $5 \cdot 10^{-4} \mathrm{~s}^{-1}$ ). To avoid possible diffusion problems, the kinetics at low $\mathrm{pH}$ were monitored by 
classical spectrophotometry in $1 \mathrm{~cm}$ cells at $25^{\circ} \mathrm{C}$. The $\mathrm{NaL}^{\prime} \mathrm{xH}_{2} \mathrm{O}$ and $\mathrm{HL}$ stock solutions were prepared as described above and mixed with aqueous $\mathrm{HCl}$ to obtain the desired $\mathrm{pH}$.

(c) Data analysis. All kinetic runs were analyzed with the program Specfit,[Binstead, 2000 \#4869] while the fitting of the kinetic model to the observed first order rate constants as a function of pH (see Results) was carried out with the program CurveFit.[Raner, 1992 \#2239]

Preparation and characterization of HL'. $\mathrm{NaL}^{\prime} \mathrm{xH}_{2} \mathrm{O}(0.050 \mathrm{~g})$ was dissolved in aqueous hydrochloric acid $(0.01 \mathrm{M}, 250 \mathrm{~mL})$. The resulting red-violet solution $\left(\lambda_{\max }=520 \mathrm{~nm}\right)$ was evaporated to dryness in a vacuum freeze dryer. The residue was thorougly washed with water and dried in air. A microcrystalline dark brown powder was obtained $(0.030 \mathrm{~g})$, which was analyzed as $\mathrm{HL}^{\prime} \cdot 1.3 \mathrm{H}_{2} \mathrm{O}$. Calcd. C, 52.37; H, 2.31; N, 37.49. Found: C, 51.53; H, 2.20; N, 38.23. IR (KBr pellets 0.75\% w/w and nujol mulls): $v_{\max } 2224(\mathrm{CN}), 1654,1526,1378 \mathrm{~cm}^{-1}$ (all intense bands). Visible spectrum (THF): $\lambda_{\max } 520,580(\mathrm{sh}) \mathrm{nm}$ (freshly prepared solution).

Computational details. All calculations were carried out by density functional theory (DFT) methods with the Gaussian98 package,[Frisch, 1998 \#5021] using the B3LYP functional[Becke, $1993 \# 2918]$ and the LANL2DZ basis set. The starting geometries for the optimization of $\mathrm{HL}$ and L'- were taken from the corresponding X-ray structures,[Fares, 1995 \#4905; Fares, 1995 \#4914] while those of $\mathrm{L}^{-}$and HL' were adapted from these by removal and addition of a proton. The dielectric effect of the aqueous solvent was included with use of the Polarizable Continuum Medium (PCM) method[Tomasi, 1994 \#5022] of Tomasi and coworkers in the Integral Equation Formalism (IEF) version using the cavity built with the United Atom Topological Model.[Barone, 1997 \#5023] This routine is included in the Gaussian package. The energies reported are the total solute free energies including the nonelectrostatic contribution due to cavitation, dispersion, and repulsion energies. 


\section{Results}

\section{(a) Spectroscopic and synthetic studies}

Compound HL is stable only in the solid state or in anhydrous organic solvents. Its visible absorption spectrum shows a broad absorption band centered at ca. $580 \mathrm{~nm}$ as already described in previous studies.[Fares, 1995 \#4905] The addition of water or buffered aqueous solutions at $\mathrm{pH}>5$ to organic solutions of HL provokes a rapid spectral evolution indicating the disappearance of $\mathrm{HL}$ and the formation of $\mathrm{L}^{-}$, which is characterized by a stronger band centered at ca. $560 \mathrm{~nm}$. The visible spectrum of this species has also been described in previous studies.[Bonamico, $1998 \# 4916]$ The addition of acidic solutions, on the other hand, leads to a more complex evolution. In addition, at low $\mathrm{pH}(<2)$ an irreversible decomposition with a $\mathrm{pH}$ dependent rate takes place to afford a species which is characterized by an absorption band centered at $490 \mathrm{~nm}$. The kinetics of these isomerization and decomposition processes have been examined (type 1 experiments) and will be presented in a subsequent section.

Compound $\mathrm{L}^{-1}$ has been used in the present study as the sodium salt, which is soluble in water and stable in the $\mathrm{pH}$ range 6-14. Acidification of this solution below $\mathrm{pH} 6$ produces an instantaneous change (within the time of mixing in the stopped-flow cell) of the visible spectrum, yielding a new band which is centered at $525 \mathrm{~nm}($ at $\mathrm{pH}<$ ca. 2). Following this acidification process, the spectrum further changes slowly to yield a final equilibrium situation which involves the formation of $\mathrm{HL}$ and which is a function of $\mathrm{pH}$. The kinetics of this equilibration process has been investigated by the type 2 experiments (vide infra). 
The speed of the protonation process of $\mathrm{L}^{\prime-}$ is consistent with the new species at $525 \mathrm{~nm}$ being the protonated form of $\mathrm{L}^{\prime}, \mathrm{HL}$, without molecular rearrangement (e.g. to a closed isomer). This transformation is fully reversible: raising the $\mathrm{pH}$ above 6 restores the spectrum of $\mathrm{L}^{-2}$. At $\mathrm{pH}$ $<2$ a subsequent irreversible change occurs, due to the decomposition of HL mentioned above. However, since the isomerization of HL' to HL becomes slower at lower $\mathrm{pH}$ values (see Results section), solutions of $\mathrm{HL}^{\prime}$ at very low $\mathrm{pH}$ are quite stable, more so than solutions of its isomer HL at the same $\mathrm{pH}$, giving a preliminary indication that the decomposition of HL' may indeed proceed via an initial isomerization to HL.

The initial spectra (ca. $1 \mathrm{~ms}$ ) during type 2 experiments as a function of $\mathrm{pH}$ are shown in Figure 1. A Specfit analysis of these spectra yields the acidity constant of $\mathrm{HL}^{\prime}\left(\mathrm{p} K_{\mathrm{a}}^{\prime}=3.63 \pm 0.01\right)$.

$<$ Figure 1 $>$

Unfortunately, it has not been possible to fully characterize compound HL', because of its instability in solution. Even in anhydrous organic solvents, e.g. THF, it isomerizes to HL in a few hours. On the basis of the IR spectrum an open structure for HL' similar to that of L'-, as expected ( 1 or $\mathbf{2}$, see Computational Studies in section (d) below), can be proposed. As a matter of fact, the IR band pattern of HL' $\left(2224,1654,1526,1378 \mathrm{~cm}^{-1}\right)$, see Figure 2, is very close to that of $\mathrm{NaL}^{\prime}\left(2220,1640,1534,1348 \mathrm{~cm}^{-1}\right)$ and significantly different from that of $\mathrm{HL}$, the latter consisting of a greater number of bands in the same region $(2235,1667,1598,1517,1485,1378$, $\left.1266 \mathrm{~cm}^{-1}\right)$. The higher energy portion of the spectrum, where the symmetric N-H stretching band occurs, is not similarly informative for the purposes of this comparison, because both 
energy and shape of this band are affected by the hydrogen bonds in the solid state.[Fares, 1995 \#4914]

$<$ Figure $2>$

\section{(b) Ring opening/closing kinetics: from HL (type 1)}

These experiments were carried out starting from a pure solution of HL (see details in the Experimental section). Since the decomposition of HL is very slow (ca. $10^{-4} \mathrm{~s}^{-1}$ ) at $\mathrm{pH} 1$, the starting solutions of HL were prepared by diluting stock solutions of the compound in $\mathrm{MeCN}$ with $0.1 \mathrm{M} \mathrm{HCl}$. The sparing solubility of HL in neat water prevented us to carry out our studies under pure aqueous conditions.

b1. From pH 5 to pH 13. These experiments involve the quantitative opening reaction of HL, giving $\mathrm{L}^{-}$. At $\mathrm{pH}<\mathrm{ca} .8$, a direct transformation of $\mathrm{HL}$ to $\mathrm{L}^{\prime-}$ without the observation of intermediates takes place. The band centered at $580 \mathrm{~nm}$ for HL is replaced by the $560 \mathrm{~nm}$ band of $\mathrm{L}^{\prime-}$ by a $\mathrm{pH}$ dependent first order rate constant. At $\mathrm{pH}>8$, however, the initial spectra are characterized by the presence of a new band centered at $660 \mathrm{~nm}$, which subsequently disappears in a first-order decay process to yield L'-. Figure 3 shows the spectral evolution in a typical run at $\mathrm{pH}$ 9.20. At high $\mathrm{pH}$ values $(>9)$, the rate constant of this process becomes $\mathrm{pH}$ independent. These transformations are irreversible, because the treatment of $\mathrm{L}^{\prime-}$ under low $\mathrm{pH}$ conditions does not afford pure HL but rather an equilibrium mixture of different species whose ratio depends on the $\mathrm{pH}$ (see type 2 kinetic runs below).

$<$ Figure $3>$ 
The first order rate constants for the isomerization processes $\left(k_{\text {iobs }}\right)$ at the various $\mathrm{pH}$ are collected in Table 1 and are shown graphically in Figure 4. The above observations are in agreement with (i) the existence of form $\mathrm{L}^{-}\left(\lambda_{\max }\right.$ ca. $\left.660 \mathrm{~nm}\right)$ which forms instantaneously by deprotonation of $\mathrm{HL}$ at high $\mathrm{pH}$ and (ii) quantitative, $\mathrm{pH}$ independent opening of $\mathrm{L}^{-}$to $\mathrm{L}^{\prime}$. At $\mathrm{pH}$ $>8$, the opening reaction is so fast that the first recorded spectra already show the presence of a large amount of $\mathrm{L}^{-}$(e.g. see Figure 3 ) in addition to $\mathrm{L}^{-}$and HL. It is to be remarked that the $\lambda_{\max }$ of the band assigned to $\mathrm{L}^{-}$is close to that observed for all the $\mathrm{ML}_{2}$ derivatives, where the closed form of the $\mathrm{L}^{-}$ligand has been verified by X-ray crystallography.[Bonamico, 1989 \#4915; Bonamico, 1991 \#4906; Bonamico, 1992 \#4907; Bonamico, 1993 \#4908; Bonamico, 1993 \#4909]

$<$ Table 1 and Figure 4>

b2. At $\mathrm{pH}$ between 2 and 5. Under these $\mathrm{pH}$ conditions, the opening reaction is not quantitative, but rather leaves a certain $\mathrm{pH}$-dependent fraction of $\mathrm{HL}$ at equilibrium. In addition, the final form of the opened isomer of the ligand also depends on $\mathrm{pH}$, a mixture of $\mathrm{L}^{-}$and $\mathrm{HL}^{\prime}$ being obtained in this $\mathrm{pH}$ range according to Figure 1. The extrapolated equilibrium spectrum is correctly analyzed by Specfit as a mixture of the initial closed form HL and the mix of the opened species $\mathrm{HL}^{\prime}$ and $\mathrm{L}^{\prime}$. The observed isomerization rate constants obtained by this method ( $k_{\text {iobs }}$ in Table 1) correspond to those of the type 2 experiments in the same $\mathrm{pH}$ interval (vide infra). The latter, however, were determined more accurately and a more complete equilibration study has therefore been carried out starting from $\mathrm{L}^{\prime}($ see section (c)). 
b3. At lower pH. As mentioned above, compound HL decomposes at low $\mathrm{pH}$ values. The decomposition is a $\mathrm{pH}$ dependent first order process, the rate constants $\left(k_{\mathrm{d}}\right)$ at $\mathrm{pH}<0.5$ being directly obtained from clean first order decay processes that are not affected by the isomerization to the open isomer HL' (see Table 1). Evidently, the isomerization of HL is too slow under these conditions to effectively compete with the decomposition process.

\section{(c) Ring opening/closing kinetics: from $\mathrm{L}^{\prime-}$ (type 2)}

These experiments have been carried out between $\mathrm{pH} 0.60$ and 4.97 and involve the reversible closing reaction of $\mathrm{L}^{\prime}$. At $\mathrm{pH}>4.97$ the extent of $\mathrm{HL}$ formation at equilibrium is not sufficient to allow the extraction of sufficiently precise rate constants. At $\mathrm{pH} \geq 2$, the equilibration can be handled as a pure 1 st order process, yielding the $k_{\text {iobs }}$ values reported in Table 1. The knowledge of the spectrum of the pure closed form allows a kinetic data analysis in terms of the forward (closing of $\left.\mathrm{HL}^{\prime} / \mathrm{L}^{\prime}, k_{\mathrm{i}^{+}}\right)$and reverse (opening of $\left.\mathrm{HL}, k_{\mathrm{i}}\right)$ components $\left(k_{\mathrm{i}^{+}}+k_{\mathrm{i}_{-}}=\right.$

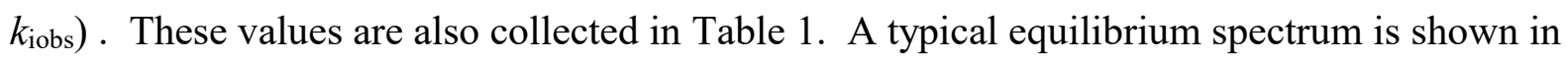
Figure 5 .

$<$ Figure 5 $>$

At $\mathrm{pH}<2$, on the other hand, the subsequent irreversible decomposition of HL, which becomes faster as the $\mathrm{pH}$ becomes smaller, becomes increasingly important while the isomerization process becomes in turn slower at lower $\mathrm{pH}$ values. A Specfit analysis with the A

$\rightleftarrows \mathrm{B} \longrightarrow \mathrm{C}$ model, however, yields useful values of $k_{\mathrm{i}^{+}}, k_{\mathrm{i}-\text {, }}$ and $k_{\mathrm{d}}$ for experiments down to $\mathrm{pH} 0.6$ (reported in Table 1). At lower $\mathrm{pH}$, the isomerization rate is too slow for significant 
rate data to be determined. The results of a typical analysis ( $\mathrm{pH} 1.30)$ are shown in Figure 6. It should be remarked that the spectrum of the final decomposition product (species C) is computed by Specfit and corresponds within experimental error to that obtained from the direct decomposition of HL from the type 1 experiments.

$<$ Figure 6 $>$

All values of $k_{\mathrm{iobs}}, k_{\mathrm{i}+}, k_{\mathrm{i}-\text {, and }} k_{\mathrm{d}}$ from type 1 and type 2 experiments in Table 1 are graphically shown in Figure 4 as a function of $\mathrm{pH}$. It is worth noting that the $k_{\mathrm{i}+}$ and $k_{\mathrm{i}-\text { values }}$ obtained from the two different analyses of type 2 experiments show continuity as a function of $\mathrm{pH}$. The values of $k_{\text {iobs }}$ obtained from type 1 and type 2 experiments, including those calculated as $\left(k_{\mathrm{i}+}+k_{\mathrm{i}-}\right)$ at $\mathrm{pH}<2$, are equally placed on a continuum curve. The $k_{\text {iobs }}$ in the $\mathrm{pH}>5$ region (where the opening reaction is quantitative) are nicely aligned with the $k_{\text {i- }}$ data of the $\mathrm{pH}<5$ region. Finally, the values of $k_{\mathrm{d}}$ from the two different kinetic analyses of type 1 and 2 experiments are again aligned on a continuum curve (straight line). Thus, all data from all types of experiments are internally consistent. Figure 4 also shows the ratio of opening and closing rate constants, $K_{\mathrm{i}}=k_{\mathrm{i}+} / k_{\mathrm{i}-}$, representing the ratio between the global concentration of the closed and opened isomers in all of their forms as a function of $\mathrm{pH}$, see equation 1 . The anionic form of the closed species, $\mathrm{L}^{-}$, is never present at equilibrium in any appreciable concentration.

$$
K_{\mathrm{i}}=\frac{k_{\mathrm{i}+}}{k_{\mathrm{i}-}}=\frac{[\mathrm{HL}]_{\mathrm{eq}}+\left[\mathrm{L}^{-}\right]_{\mathrm{eq}}}{\left[\mathrm{HL}^{\prime}\right]_{\mathrm{eq}}+\left[\mathrm{L}^{\prime-}\right]_{\mathrm{eq}}}=\frac{[L]_{\mathrm{eq}}}{\left[L^{\prime}\right]_{\mathrm{eq}}}
$$




\section{(d) Computational studies: structure of HL' and L'-}

As species $\mathrm{HL}^{\prime}$ and $\mathrm{L}^{-}$(in a free state, i.e. not coordinated to a transition metal) have not been previously described and their instability prevented us from obtaining detailed structural information, we have carried out computational studies on these species. In addition, we have also investigated the well known HL and L'- congeners in order to probe the validity of the computational method and to verify the energetics of the isomerization process on both neutral and ionic forms. The common numbering scheme used for the open and closed isomers is illustrated in Chart 2. The energetic results are summarized in Figure 7 and the relevant optimized geometric parameters are collected in Table 2.

$<$ Chart 2, Figure 7 and Table 2>

The structures of forms $\mathrm{L}^{-}$and HL were optimized starting from the experimental structures as determined by X-ray crystallography. The structure of the closed anionic form $\mathrm{L}^{-}$has been calculated by removing an exo proton from the amino group of HL. In this way, the remaining endo proton may establish a stabilizing intramolecular H-bonding interaction with the lone pair of the imino group on the other 5-member ring. The alternative isomers where the two imino protons are either both endo or both exo were considered less likely. The endo/endo isomer was not calculated. The exo/exo isomer, on the other hand, was calculated for two reasons. First, this conformation is experimentally found in all transition metal complexes of $\mathrm{L}^{-}$. Second, we wanted to verify the stabilizing effect of the intramolecular $\mathrm{H}$ bonding interaction and evaluate its importance. The exo/exo isomer was indeed found higher in energy as expected, the difference relative to the endo/exo isomer being $6.4 \mathrm{kcal} / \mathrm{mol}$ for the isolated ions. 
Concerning the open neutral species HL', this can be generated in principle by addition of a proton to L'- at either the pyrrolyl nitrogen atom to yield the 2-tricyanovinyl-3,4-dicyano-5amino-1H-pyrrole form (1), at the nitrogen atom of the amino substituent to yield a zwitterionic 2-(5-ammonio-3,4-dicyano-2H-pyrrol-2-ylidene)-1,1,2-tricyanoethanide form (2), or at the $\beta$ carbon atom of the tricyanovinyl group. Discarding the latter possibility which would disrupt the vinyl conjugation with the pyrrole ring, the other two possibilities were both considered and the corresponding geometries optimized. As a result, form 2 turned out to be $34 \mathrm{kcal} / \mathrm{mole}$ less stable than form $\mathbf{1}$, suggesting that the structure of $\mathrm{HL}^{\prime}$ is as shown in $\mathbf{1}$. It can be noted that, besides the absence of a charge separation, structure 1 also benefits from an extended $\pi$ delocalization on the amino substituent.

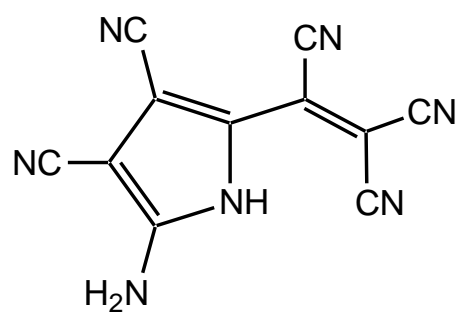

1<smiles>N#CC(C#N)=C(C#N)c1[nH]c([NH3+])c(C#N)c1C#N</smiles>

2

An isomeric structure for the anion $\mathrm{L}^{\prime-}$ was also considered, namely a tautomer having an imino group at the $\mathrm{C} 2$ position and a proton on N1. However, besides not corresponding to the crystallographically determined structure, a much higher energy (45 kcal/mol) was calculated for this optimized structure.

As shown in Figure 7, the calculations in vacuum (energy values in parentheses) yield a more stable closed isomer for the acid by $11.1 \mathrm{kcal} \mathrm{mol}^{-1}$ and also a more stable closed isomer for 
the conjugate base by only $0.3 \mathrm{kcal} \mathrm{mol}^{-1}$. Both results slightly overestimate the relative stability of the closed form, since the observed 4:1 equilibrium between HL and HL' corresponds to a $\Delta \mathrm{G}$ $=0.8 \mathrm{kcal} / \mathrm{mol}$ while the quantitative transformation of $\mathrm{L}^{-}$to $\mathrm{L}^{\prime}$ (equilibrium ratio $<1: 100$ ) implies that the latter is at least $2.7 \mathrm{kcal} / \mathrm{mol}$ lower in free energy. No significant entropic contribution is expected in these isomerization processes, thus $\Delta \mathrm{G} \approx \Delta \mathrm{H} \approx \Delta \mathrm{E}$. We considered that the neglect of solvation energy could be partly responsible for this discrepancy, thus we repeated the calculations with the solvent as a polarizable continuum model.[Tomasi, 1994 \#5022] Although the situation is improved for the neutral species, it becomes worse for the anionic one. The neglect of explicit hydrogen bonding interactions between the organic molecules and water could account for the remaining discrepancy. Indeed, the closed forms $\mathrm{L}^{-}$ and $\mathrm{HL}$ are characterized by a greater extent of intramolecular $\mathrm{H}$ bonding and consequently should be stabilized to a lesser extent by the intermolecular $\mathrm{H}$ bonding with the solvent. On the other hand, it is also possible that the $\mathrm{H}$ bonding interactions with water are more favourable than the intramolecular $\mathrm{H}$ bonding interactions. Thus, a more representative form for $\mathrm{L}^{-}$in water would be the exo/exo conformer which has indeed a higher energy than the $\mathrm{L}^{\prime}$ isomer $(6.1$ $\mathrm{kcal} / \mathrm{mole}$ from the gas-phase calculation and only $0.1 \mathrm{kcal} / \mathrm{mol}$ from the PCM calculation). The explicit neglect of the $\mathrm{H}$ bonding interactions with water could account for any residual discrepancy. Nevertheless, the disagreement between theory and experiment remains within the few kcal mol-1 that are usually considered as customary for the density functional methodologies.

An analysis of the geometries in Table 2 confirms the suitability of the chosen computational method. The optimized geometries for the known compounds L'- and HL match pretty closely the experimentally determined structures. Certain calculated distances are closer to experiment for the structures optimized in vacuum, others for the structure optimized in water. 
As the experimental structures were obtained in the crystalline state, neither of the calculation can in fact be directly compared with the experiment. The largest discrepancy is observed in the C-N distances of the cyano groups, for which the vacuum and water calculations show values that are close to each other and systematically longer than $1.18 \AA$, while the corresponding experimental values are 0.04-0.07 $\AA$ shorter. Otherwise, the agreement between calculated and experimental values is excellent, the calculated values being in general a bit longer with only few exceptions.

\section{Discussion}

\section{(a) Acid/base equilibria and isomerization rates}

We shall first examine the acid/base and isomerization behaviour of the $\mathrm{HL} / \mathrm{L}^{-}$system without consideration of the acid decomposition process. The kinetic and spectroscopic studies have revealed the existence of the basic form of the closed species, $\mathrm{L}^{-}$, and the acidic form of the

open species, HL'. The protonation/deprotonation processes within each isomer are, as expected, extremely fast while the isomerization is rate limiting. The kinetic model is therefore based on the square Scheme 1, where the proton transfer (vertical) processes are supposed to be instantaneously achieved and at equilibrium at all times.

$<$ Scheme 1 $>$

Given expression (1), the kinetic model can be treated as a simple first order equilibration between species $\mathcal{L}$ and $\mathcal{L}^{\prime}$, according to Scheme 2 , justifying the observation of isosbestic points 
for all kinetic runs (except those involving further decomposition at low pH values, see Results section). The values of $k_{\mathrm{i}+}$ and $k_{\mathrm{i} \text { - }}$ at different $\mathrm{pH}$ are available experimentally (Table 1) as illustrated in the Results section. Under the conditions in which $k_{\mathrm{i}_{-}}>>k_{\mathrm{i}_{+}}(\mathrm{pH}>6)$ a quantitative opening of $\mathcal{L}$ is observed.

$<$ Scheme 2>

It can be easily shown (annex I) that $k_{\mathrm{i}-\text { and }} k_{\text {i+ }}$ are related to the kinetic and equilibrium parameters of Scheme 1 according to equations 2 and 3, respectively.

$$
\begin{aligned}
& k_{\mathrm{i}-}=\frac{k_{0-}+k_{1-}\left[\mathrm{H}^{+}\right] / K_{\mathrm{a}}}{1+\left[\mathrm{H}^{+}\right] / K_{\mathrm{a}}} \\
& k_{\mathrm{i}+}=\frac{k_{0+}+k_{1+}\left[\mathrm{H}^{+}\right] / K_{\mathrm{a}}^{\prime}}{1+\left[\mathrm{H}^{+}\right] / K_{\mathrm{a}}^{\prime}}
\end{aligned}
$$

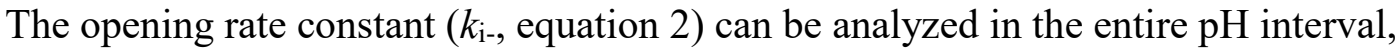
spanning a rate range of ca. 7 orders of magnitude, although this becomes a quantitative process $\left(k_{\mathrm{i}^{+}}<<k_{\mathrm{i}-} \approx k_{\mathrm{iobs}}\right)$ only at $\mathrm{pH}>$ ca. 5 (see Figure 4$)$. The shape of the curve passing through all the experimental points indicates that at a high $\mathrm{pH}$, both $\left[\mathrm{H}^{+}\right]$-dependent terms in equation 2 become negligible and the limiting value of $k_{\text {iobs }}=k_{\mathrm{i}-}$ is therefore equal to $k_{0-}$ (the ring opening rate for $\mathrm{L}^{-}$). As the $\mathrm{pH}$ is lowered, the function enters a wide $\mathrm{pH}$ interval (between ca. 2 and 8) where $\log$ $k_{\mathrm{i}-}$ is linearly dependent on $\mathrm{pH}$ with slope 1 . This signifies that while the $\left[\mathrm{H}^{+}\right] / K_{\mathrm{a}}$ term becomes important in the denominator, the numerator term $k_{1-[}\left[\mathrm{H}^{+}\right] / K_{\mathrm{a}}$ remains negligible relative to $k_{0-\text {. }}$ 
Thus, equation 2 can be simplified to equation 4 down to ca. $\mathrm{pH} 2$. This means that, in that region, compound $\mathrm{HL}$ isomerizes mainly via its conjugate base $\mathrm{L}^{-}$, following a fast deprotonation pre-equilibrium.

$$
k_{\mathrm{i}-}=\frac{k_{0-}}{1+\left[\mathrm{H}^{+}\right] / K_{\mathrm{a}}^{\prime}} \quad(\mathrm{pH}>2)
$$

The break point between the two linear regions of slopes 1 and 0 affords the value of the $\mathrm{p} K_{\mathrm{a}}$, which is $8.61 \pm 0.03$ by fitting of equation 4 to the experimental data. This fitting also affords $\log k_{0-}=2.58 \pm 0.03\left(k_{0-}=3.8(3) \cdot 10^{2} \mathrm{~s}^{-1}\right)$. A curvature leading to a second break point for $k_{\mathrm{i} \text { - }}$ is visible in Figure 4 at low $\mathrm{pH}$. This is the region in which the numerator term $k_{1-}\left[\mathrm{H}^{+}\right] / K_{\mathrm{a}}$ of equation 2 starts to become non negligible. A global fitting of equation 2 to the $k_{\text {i- }}$ data yields $\log$ $k_{1-}=-5.37 \pm 0.12\left(k_{1-}=4.3(1.2) \cdot 10^{-6} \mathrm{~s}^{-1}\right)$, the rate of ring opening of the acidic form HL.

The closing reaction $\left(k_{\mathrm{i}+}\right.$, equation 3$)$ can only be analyzed in the $\mathrm{pH}$ interval between 0.6

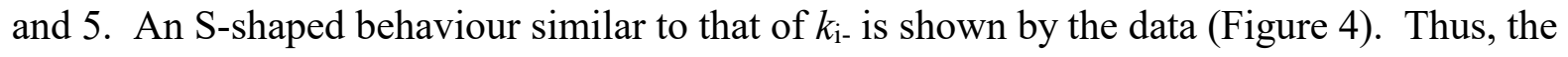
high $\mathrm{pH}$ region gives rise to a constant value for $k_{\mathrm{i}+}=k_{0+}=1.62(7) \cdot 10^{-2} \mathrm{~s}^{-1}\left(\log k_{0^{+}}=-1.79 \pm 0.02\right)$. Down to $\mathrm{pH} 2$ the closing reaction of $\mathrm{L}^{-}$takes place mainly via closing of the anionic form $\left(k_{0^{+}}\right)$ to afford $\mathrm{L}^{-}$, followed by instantaneous protonation. The protonation equilibrium of $\mathrm{L}^{-}\left(K_{\mathrm{a}}^{\prime}\right)$ slows the reaction by sequestering starting material into the less reactive acidic form. The break point of the curve corresponds to the $\mathrm{p} K_{\mathrm{a}}^{\prime}$, which is calculated as $3.62 \pm 0.02$ by fitting of the $k_{\mathrm{i}+}$ experimental data. This value is identical within experimental error to that determined as shown in section (a) of Results and Figure 1, $\left(\log K_{\mathrm{a}}^{\prime}=3.63 \pm 0.01\right)$, further indicating the internal 
consistency and correctness of the model. Fitting equation 3 with all the $k_{\mathrm{i}+}$ data affords the value of $k_{1+}=1.8(2) \cdot 10^{-5} \mathrm{~s}^{-1}\left(\log k_{1+}=-4.75 \pm 0.06\right)$.

The knowledge of all rate and ionization constants allows us to analyze the interconversion between the closed and open forms $\mathcal{L}^{\prime}$ and $\mathcal{L}$ in terms of the two possible pathways of the square

Scheme $1\left(k_{\text {iobs }}=k_{0 \mathrm{obs}}+k_{1 \mathrm{obs}}\right.$, where $k_{0 \mathrm{obs}}$ and $k_{1 \mathrm{obs}}$ are given by eq. 5 and 6$)$. As shown in Figure 8, the isomerization takes place preferentially via the anionic form at $\mathrm{pH}>0.67$.

$$
\begin{aligned}
& k_{0 \mathrm{obs}}=\frac{k_{0+}}{1+\left[\mathrm{H}^{+}\right] / K_{\mathrm{a}}^{\prime}}+\frac{k_{0-}}{1+\left[\mathrm{H}^{+}\right] / K_{\mathrm{a}}} \\
& k_{1 \mathrm{obs}}=\frac{k_{1+}}{K_{\mathrm{a}}^{\prime} /\left[\mathrm{H}^{+}\right]+1}+\frac{k_{1-}}{K_{\mathrm{a}} /\left[\mathrm{H}^{+}\right]+1}
\end{aligned}
$$

$<$ Figure $8>$

All the determined rate constants also allow us to calculate equilibrium constants for the isomerization process in the basic, anionic state $\left(\log K_{0}=\log \left(k_{0+} / k_{0-}\right)=-4.37 \pm 0.04\right)$ and in the acidic, neutral state $\left(\log K_{1}=\log \left(k_{1+} / k_{1-}\right)=0.62 \pm 0.13\right)$. It is important to notice that the low $\mathrm{pH}$ breakpoint value of the $k_{\mathrm{i}+}$ curve (at $\mathrm{pH}=0.66 \pm 0.09$ ) corresponds within experimental error to the

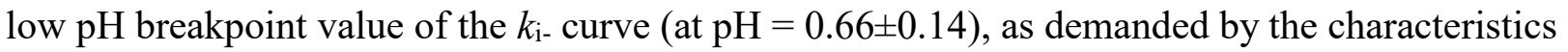
of the square scheme $\left(K_{\mathrm{a}}^{\prime} K_{0}=K_{\mathrm{a}} K_{1}\right)$. This is yet another check that our kinetic and equilibrium data are internally consistent. The ratio $k_{\mathrm{i}+} / k_{\mathrm{i}-}=K_{\mathrm{i}}$ as defined in equation 1 , namely the ratio between closed and open isomers in all their forms, is also represented in Figure 4. The theoretical curve fitting these experimental points is calculated from all acidity and rate constants 
in Scheme 1. According to our model, $K_{\mathrm{i}}$ becomes the $\mathrm{pH}$-independent isomerization equilibrium constant for the acidic forms, $K_{1}$, at low $\mathrm{pH}$ whereas it converges to the $\mathrm{pH}$-independent isomerization equilibrium constant of the basic forms, $K_{0}$, at high $\mathrm{pH}$. These two horizontal asymptotes are shown by the two dashed lines in Figure 4. The individual fractional distribution

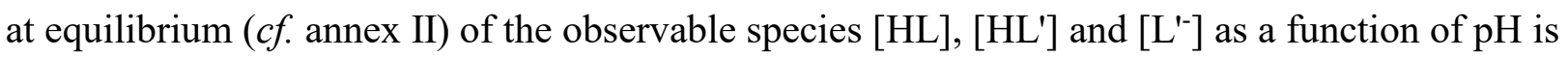
shown in Figure 9.

$<$ Figure 9 $>$

From Figure 9 it can be observed that [ $\left.\mathrm{L}^{\prime}\right]$ will be essentially the only species present in solution at $\mathrm{pH}>6$, whereas the maximum equilibrium concentration of [HL] (79\%) is attained at $\mathrm{pH} \leq 2$. The species distribution of Figure 9 is valid, of course, only in the absence of HL decomposition. Compound HL can be isolated as a pure material from acidic water solutions only thanks to its lower solubility relative to HL'. Once HL is redissolved in acidic solutions, it is kinetically rather stable. On the other hand, pure solutions of HL' can only be kinetically generated upon acidification of solutions of $\mathrm{L}^{\prime}$. Finally, $\mathrm{L}^{-}$can only be observed as a fleeting intermediate and rapidly isomerizes to the thermodynamically more stable $\mathrm{L}^{\prime}$, although it is stabilized by coordination to transition metals as shown previously.[Bonamico, $1989 \# 4915$; Bonamico, 1991 \#4906; Bonamico, 1992 \#4907; Bonamico, 1993 \#4908; Bonamico, 1993 \#4909]

\section{(b) Decomposition of $\mathrm{HL}$}


The kinetic measurements show that compound HL decomposes under strongly acidic conditions ( $\mathrm{pH}<2$ ), while HL' decomposes only via its preliminary isomerization to HL. Since the isomerization of HL' to $\mathrm{HL}\left(k_{1+}\right)$ is extremely slow, solutions of HL' are quite stable under strongly acidic conditions. As shown in Figure 4, the decomposition of HL follows a rate law which is first order in $\left[\mathrm{H}^{+}\right]$. This is consistent with a rapid protonation equilibrium, followed by rate-determining decomposition of the protonated species $\mathrm{H}_{2} \mathrm{~L}^{+}$(Scheme 3). No deviation from linearity for the $\log k_{\mathrm{d}} v s . \mathrm{pH}$ data is apparent from Figure 4 , indicating that the $\mathrm{p} K_{\mathrm{a}}$ value for the $\mathrm{H}_{2} \mathrm{~L}^{+}$species is lower than -1 .

$<$ Scheme 3>

\section{Conclusions}

All the kinetic and thermodynamic parameters concerning the acid-base and isomerization equilibria involving $\mathrm{HL}$ and L'- have been determined. They are based on a model whose consistency has been checked on several points. We would like to make reference to other studies where kinetic models similar to that used here have allowed sorting the acid dissociation constants and the rates of reversible chemical equilibria.[Strehlow, 1962 \#5002; Chiang, 1988 \#4994; Chiang, 1992 \#4995; Legouin, 1999 \#4999] We are not aware, however, of precedents for the complete determination of all forward and reverse chemical rate constants and acid dissociation constants for a square scheme such as that illustrated in the present study.

Further progress in the chemistry of $\mathrm{HL}$ and/or $\mathrm{L}^{-}$is now possible taking advantage of the information gathered with the present study. On the other hand, the successful applications of 
these materials ultimately depends on the feasibility of their chemical derivatization. As a matter of fact, after the initial attempts to exploit HL, $\mathrm{L}^{-}$or $\mathrm{ML}$ in sensor devices, as mentioned above, we are now considering the modification of these species through chemical substitution for more advanced applications such as, for instance, monolayers covalently bound to the surface of crystalline silicon, or LB films. The information gained on the HL/L'- system with the current work is highly valuable for further development along these directions.

\section{Annex I}

Given relation (1) and the $\mathrm{p} K_{\mathrm{a}}$ relations,

$$
\begin{aligned}
& {[\mathcal{L}]=\left[\mathrm{L}^{-}\right] \alpha} \\
& {\left[\mathcal{L}^{\prime}\right]=\left[\mathrm{L}^{\prime-}\right] \alpha^{\prime}}
\end{aligned}
$$

where $\alpha=\left\{1+\left[\mathrm{H}^{+}\right] / K_{\mathrm{a}}\right\} \quad$ and $\quad \alpha^{\prime}=\left\{1+\left[\mathrm{H}^{+}\right] / K_{\mathrm{a}}^{\prime}\right\}$

For the equilibration of Scheme 1,

$$
\begin{aligned}
\mathrm{v} & =\left\{k_{0^{+}}\left[\mathrm{L}^{-}\right]+k_{1_{+}}\left[\mathrm{HL}^{\prime}\right]\right\}-\left\{k_{0-}\left[\mathrm{L}^{-}\right]+k_{1-[}[\mathrm{HL}]\right\}=\left\{k_{0^{+}}+k_{1+}\left[\mathrm{H}^{+}\right] / K_{\mathrm{a}}^{\prime}\right\}\left[\mathrm{L}^{-}\right]-\left\{k_{0_{-}}+k_{1_{-}-}\left[\mathrm{H}^{+}\right] / K_{\mathrm{a}}\right\}\left[\mathrm{L}^{-}\right] \\
& =\beta^{\prime}\left[\mathrm{L}^{-}\right]-\beta\left[\mathrm{L}^{-}\right]
\end{aligned}
$$

where $\beta=k_{0-}+k_{1-}\left[\mathrm{H}^{+}\right] / K_{\mathrm{a}} \quad$ and $\beta^{\prime}=k_{0+}+k_{1+}\left[\mathrm{H}^{+}\right] / K_{\mathrm{a}}^{\prime}$

By using (7) and (8),

$$
\mathrm{v}=\left(\beta^{\prime} / \alpha^{\prime}\right)\left[\mathcal{L}^{\prime}\right]-(\beta / \alpha)[\mathcal{L}]
$$

Comparison with

Scheme 2 gives $\quad k_{\mathrm{i}^{+}}=\beta^{\prime} / \alpha^{\prime}$ and $k_{\mathrm{i}-}=\beta / \alpha$, i.e. equations (2) and (3). 


\section{Annex II}

The total concentration of all species at equilibrium is

$\mathrm{C}_{\mathrm{T}}=[\mathcal{L}]_{\mathrm{eq}}+\left[\mathcal{L}^{\prime}\right]_{\mathrm{eq}}=\alpha\left[\mathrm{L}^{-}\right]_{\mathrm{eq}}+\alpha^{\prime}\left[\mathrm{L}^{-}\right]_{\mathrm{eq}}$

From equation $(9)(\mathrm{v}=0$ at equilibrium):

$\left[\mathrm{L}^{-}\right]_{\mathrm{eq}} /\left[\mathrm{L}^{\prime}\right]_{\mathrm{eq}}=\beta^{\prime} / \beta$

From the combination of eqs. (10) and (11) and use of the acidity constants:
$\left[\mathrm{L}^{-}\right] / \mathrm{C}_{\mathrm{T}}=\left\{\alpha \beta^{\prime} / \beta+\alpha^{\prime}\right\}^{-1}$
(fraction of $\mathrm{L}^{-}$)
$\left[\mathrm{L}^{\prime-}\right] / \mathrm{C}_{\mathrm{T}}=\left\{\alpha+\alpha^{\prime} \beta / \beta^{\prime}\right\}^{-1}$
(fraction of $\mathrm{L}^{\prime-}$ )
$[\mathrm{HL}] / \mathrm{C}_{\mathrm{T}}=\left\{\left[\mathrm{L}^{-}\right] / \mathrm{C}_{\mathrm{T}}\right\}\left[\mathrm{H}^{+}\right] / K_{\mathrm{a}}$
(fraction of HL)
$\left[\mathrm{HL}^{\prime}\right] / \mathrm{C}_{\mathrm{T}}=\left\{\left[\mathrm{L}^{\prime}\right] / \mathrm{C}_{\mathrm{T}}\right\}\left[\mathrm{H}^{+}\right] / K_{\mathrm{a}}^{\prime}$
(fraction of HL')

Acknowledgements. RP and EC are grateful to the Conseil Régional de Bourgogne for funding that has allowed the purchase of the stopped-flow apparatus.

\section{References}


Table 1. Rate and equilibrium constants for the all transformations at various $\mathrm{pH}$ values.

\begin{tabular}{|c|c|c|c|c|c|c|c|}
\hline $\mathrm{pH}$ & $\begin{array}{c}\text { Measure- } \\
\text { ment }^{\mathrm{a}}\end{array}$ & Type $^{b}$ & $\log k_{\text {iobs }}^{c}$ & $\log k_{\mathrm{i}^{+}}^{\mathrm{c}}$ & $\log k_{\mathrm{i}-}{ }^{\mathrm{c}}$ & $\log K_{\mathrm{i}}^{\mathrm{d}}$ & $\log k_{\mathrm{d}}^{\mathrm{c}}$ \\
\hline$-0.49^{\mathrm{e}}$ & $\mathrm{A}$ & 1 & & & & & $-2.41 \pm 0.01$ \\
\hline$-0.187^{\mathrm{e}}$ & $\mathrm{A}$ & 1 & & & & & $-2.78 \pm 0.01$ \\
\hline $0.14^{\mathrm{e}}$ & $\mathrm{A}$ & 1 & & & & & $-3.11 \pm 0.01$ \\
\hline $0.42^{\mathrm{e}}$ & $\mathrm{A}$ & 1 & & & & & $-3.43 \pm 0.01$ \\
\hline $0.60^{\mathrm{e}}$ & A & 2 & & $-4.41 \pm 0.04$ & $\mathrm{f}$ & & $-3.57 \pm 0.02$ \\
\hline 1.00 & $\mathrm{~A}$ & 2 & & $-4.29 \pm 0.01$ & $-4.80 \pm 0.03$ & 0.51 & $-3.94 \pm 0.04$ \\
\hline 1.30 & A & 2 & & $-4.11 \pm 0.03$ & $-4.73 \pm 0.05$ & 0.62 & $-4.20 \pm 0.02$ \\
\hline 1.60 & $\mathrm{~A}$ & 2 & & $-3.80 \pm 0.01$ & $-4.42 \pm 0.01$ & 0.62 & $-4.57 \pm 0.09$ \\
\hline 2.00 & $\mathrm{~A}$ & 2 & $-3.34 \pm 0.01$ & & & & \\
\hline 2.00 & $\mathrm{~B}$ & 2 & $-3.32 \pm 0.01$ & $-3.45 \pm 0.01$ & $-3.99 \pm 0.02$ & 0.54 & \\
\hline 2.30 & B & 2 & $-3.05 \pm 0.02$ & $-3.14 \pm 0.01$ & $-3.76 \pm 0.01$ & 0.62 & \\
\hline 2.60 & B & 2 & $-2.75 \pm 0.02$ & $-2.85 \pm 0.01$ & $-3.41 \pm 0.01$ & 0.56 & \\
\hline 2.78 & $\mathrm{~B}$ & 1 & $-2.56 \pm 0.01$ & & & & \\
\hline 2.78 & $\mathrm{~B}$ & 2 & $-2.58 \pm 0.01$ & $-2.68 \pm 0.01$ & $-3.23 \pm 0.02$ & 0.55 & \\
\hline 3.18 & $\mathrm{~B}$ & 1 & $-2.22 \pm 0.01$ & & & & \\
\hline 3.18 & B & 2 & $-2.24 \pm 0.01$ & $-2.36 \pm 0.01$ & $-2.84 \pm 0.01$ & 0.48 & \\
\hline 3.64 & B & 2 & $-1.92 \pm 0.03$ & $-2.08 \pm 0.01$ & $-2.40 \pm 0.02$ & 0.32 & \\
\hline 4.13 & $\mathrm{~B}$ & 2 & $-1.61 \pm 0.01$ & $-1.90 \pm 0.01$ & $-1.91 \pm 0.01$ & 0.01 & \\
\hline 4.66 & $\mathrm{~B}$ & 2 & $-1.23 \pm 0.01$ & $-1.83 \pm 0.01$ & $-1.33 \pm 0.01$ & -0.50 & \\
\hline 4.97 & B & 2 & $-0.99 \pm 0.04$ & & & & \\
\hline 5.60 & B & 1 & $-0.43 \pm 0.01$ & & & & \\
\hline 6.60 & B & 1 & $0.49 \pm 0.01$ & & & & \\
\hline 6.75 & B & 1 & $0.67 \pm 0.01$ & & & & \\
\hline 7.16 & $\mathrm{~B}$ & 1 & $1.07 \pm 0.01$ & & & & \\
\hline 8.22 & B & 1 & $2.10 \pm 0.01$ & & & & \\
\hline 8.72 & $\mathrm{~B}$ & 1 & $2.39 \pm 0.01$ & & & & \\
\hline 9.20 & $\mathrm{~B}$ & 1 & $2.49 \pm 0.02$ & & & & \\
\hline 10.00 & $\mathrm{~B}$ & 1 & $2.54 \pm 0.01$ & & & & \\
\hline 13.00 & B & 1 & $2.53 \pm 0.01$ & & & & \\
\hline
\end{tabular}

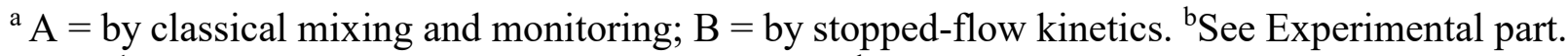
${ }^{\mathrm{c}} k$ in s ${ }^{-1}$ units. See definition in the results section. ${ }^{\mathrm{d}} K_{\mathrm{i}}=k_{\mathrm{i}+} / k_{\mathrm{i}-.}{ }^{\mathrm{e}}$ The acidity function $\mathrm{H}_{0}$ is used in place of the $\mathrm{pH}$.[Paul, 1957 \#5205] ${ }^{\mathrm{f}}$ Too slow to be determined accurately. 


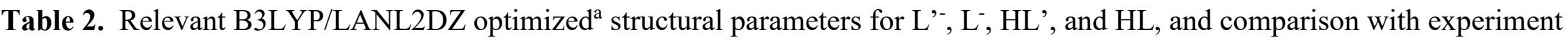
(distances in $\AA$; angles in degrees)

\begin{tabular}{|c|c|c|c|c|c|c|}
\hline \multirow[t]{2}{*}{ Parameter } & \multicolumn{2}{|c|}{$\mathrm{L}^{\prime-}$} & \multirow{2}{*}{$\begin{array}{c}\mathrm{L}^{-} \\
\text {Optim. }\end{array}$} & \multirow{2}{*}{$\begin{array}{c}\text { HL' } \\
\text { Optim. }\end{array}$} & \multicolumn{2}{|c|}{ HL } \\
\hline & Optim. & Exper. $^{\mathrm{b}}$ & & & Optim. & Exper. $^{\mathrm{c}}$ \\
\hline $\mathrm{N} 1-\mathrm{C} 2$ & $1.345 / 1.355$ & $1.341(6)$ & $1.423 / 1.449$ & $1.368 / 1.370$ & $1.375 / 1.379$ & $1.400(6)$ \\
\hline N1-C5 & $1.395 / 1.393$ & $1.389(6)$ & $1.401 / 1.410$ & $1.416 / 1.408$ & $1.402 / 1.402$ & $1.364(7)$ \\
\hline $\mathrm{N} 1-\mathrm{C} 8$ & - & - & $1.409 / 1.443$ & - & $1.418 / 1.425$ & $1.412(6)$ \\
\hline $\mathrm{C} 2-\mathrm{N} 2$ & $1.379 / 1.363$ & $1.349(7)$ & $1.301 / 1.298$ & $1.361 / 1.342$ & $1.349 / 1.339$ & $1.305(7)$ \\
\hline $\mathrm{C} 2-\mathrm{C} 3$ & $1.449 / 1.455$ & $1.420(7)$ & $1.482 / 1.469$ & $1.422 / 1.434$ & $1.429 / 1.436$ & $1.393(7)$ \\
\hline $\mathrm{C} 3-\mathrm{C} 4$ & $1.426 / 1.418$ & $1.395(7)$ & $1.418 / 1.409$ & $1.429 / 1.420$ & $1.447 / 1.441$ & $1.429(7)$ \\
\hline C3-C9 & $1.413 / 1.410$ & $1.415(8)$ & $1.414 / 1.409$ & $1.417 / 1.412$ & $1.416 / 1.410$ & $1.434(7)$ \\
\hline $\mathrm{C} 4-\mathrm{C} 5$ & $1.445 / 1.445$ & $1.414(7)$ & $1.424 / 1.414$ & $1.420 / 1.424$ & $1.405 / 1.400$ & $1.373(7)$ \\
\hline C4-C10 & $1.420 / 1.416$ & $1.446(7)$ & $1.425 / 1.419$ & $1.424 / 1.421$ & $1.422 / 1.420$ & $1.432(7)$ \\
\hline $\mathrm{C} 5-\mathrm{C} 6$ & $1.427 / 1.419$ & $1.401(7)$ & $1.413 / 1.409$ & $1.435 / 1.423$ & $1.437 / 1.429$ & $1.431(7)$ \\
\hline C6-C7 & $1.411 / 1.414$ & $1.400(7)$ & $1.432 / 1.414$ & $1.405 / 1.407$ & $1.406 / 1.401$ & $1.364(9)$ \\
\hline C6-C11 & $1.444 / 1.441$ & $1.420(7)$ & $1.423 / 1.418$ & $1.442 / 1.442$ & $1.425 / 1.424$ & $1.429(9)$ \\
\hline $\mathrm{C} 7-\mathrm{C} 8$ & $1.432 / 1.425$ & $1.429(7)$ & $1.479 / 1.472$ & $1.429 / 1.423$ & $1.489 / 1.491$ & $1.470(8)$ \\
\hline C7-C12 & $1.433 / 1.426$ & $1.427(8)$ & $1.410 / 1.406$ & $1.431 / 1.427$ & $1.415 / 1.411$ & $1.404(7)$ \\
\hline $\mathrm{C} 8 \mathrm{-N} 8$ & $1.186 / 1.186$ & $1.141(7)$ & $1.313 / 1.303$ & $1.186 / 1.185$ & $1.296 / 1.291$ & $1.268(8)$ \\
\hline C9-N9 & $1.189 / 1.187$ & $1.138(9)$ & $1.187 / 1.187$ & $1.184 / 1.184$ & $1.185 / 1.185$ & $1.115(7)$ \\
\hline C10-N10 & $1.186 / 1.185$ & $1.128(8)$ & $1.183 / 1.181$ & $1.182 / 1.182$ & $1.182 / 1.182$ & $1.120(8)$ \\
\hline C11-N11 & $1.182 / 1.181$ & $1.155(8)$ & $1.184 / 1.182$ & $1.181 / 1.180$ & $1.181 / 1.181$ & $1.129(10)$ \\
\hline C12-N12 & $1.187 / 1.186$ & $1.149(8)$ & $1.189 / 1.188$ & $1.183 / 1.184$ & $1.185 / 1.184$ & $1.143(8)$ \\
\hline
\end{tabular}

${ }^{\mathrm{a}}$ Values on the left and right refer to optimization in vacuum and water medium, respectively. ${ }^{\mathrm{b}}$ From ref. [Fares, 1995 \#4914]. ${ }^{\mathrm{c}}$ From ref. [Fares, $1995 \# 4905]$. 


\section{Captions for Figures}

Figure 1. Spectra of solutions obtained from $\mathrm{HL}$ and buffers at different $\mathrm{pH}$ at zero time.

Figure 2. IR spectra in Nujol mull of compounds HL', HL'1/2NAPH (NAPH $=1$ chloronaphthalene), and $\mathrm{NaL}^{\prime} \cdot \mathrm{xH}_{2} \mathrm{O}$.

Figure 3. Representative spectra of the time evolution in a type 1 experiment at $\mathrm{pH} 9.20$. Time $=1 \mathrm{~ms}$ (initial spectrum); $5 \mathrm{~ms}$ (intermediate spectrum); $1.9 \mathrm{~s}$ (final spectrum).

Figure 4. Plot of $\log k$ from Table 1 (rate constants in $\mathrm{s}^{-1}$ and equilibrium constants) vs $\mathrm{pH}$ or $\mathrm{H}_{0}$ (acidity function).[Paul, $\left.1957 \# 5205\right]$ The $\mathrm{H}_{0}$ values are used at $\mathrm{pH}<1$. Diamonds: global rate constants, $k_{\text {iobs; }}$ crosses: ring closing rate constants, $k_{\mathrm{i}+}$; squares: ring opening rate constants, $k_{\mathrm{i}-\text {; }}$ circles: equilibrium constants $\left(k_{\mathrm{i}+} / k_{\mathrm{i}}\right)$; triangles: decomposition rate constants, $k_{\mathrm{d}}$. The $k_{\text {iobs }}$ values at $\mathrm{pH} \geq 2$ are experimentally measured data, while those at $\mathrm{pH}<2$ are calculated from experimentally available $k_{\mathrm{i}^{+}}+k_{\mathrm{i} \text {.. }}$ The solid curves are the best fit to the data according to the model (see Discussion). 
Figure 5. Initial and equilibrium spectra for a type 2 run at $\mathrm{pH} 3.37$. The spectrum of pure HL obtained under the same conditions is also superimposed.

Figure 6. Representative spectra for a type 2 run at $\mathrm{pH}$ 1.30. A: starting spectrum; B: calculated spectrum of the HL intermediate; C: extrapolated spectrum of the decomposition product (see text).

Figure 7. Energetics for the isomerization process of $\mathrm{HL} / \mathrm{HL}^{\prime}$ and $\mathrm{L}^{-} / \mathrm{L}^{\prime-}$ according to the B3LYP/LANL2DZ calculation including solvation energies in water. The energy values in parentheses are the corresponding figures from the calculations "in vacuum”.

Figure 8. Fractional distribution of the isomerization pathways between open and closed isomers as a function of $\mathrm{pH}$.

Figure 9. Equilibrium fractional distribution of species HL, HL' and $\mathrm{L}^{\prime-}$ as a function of $\mathrm{pH}$. 
Figure 1

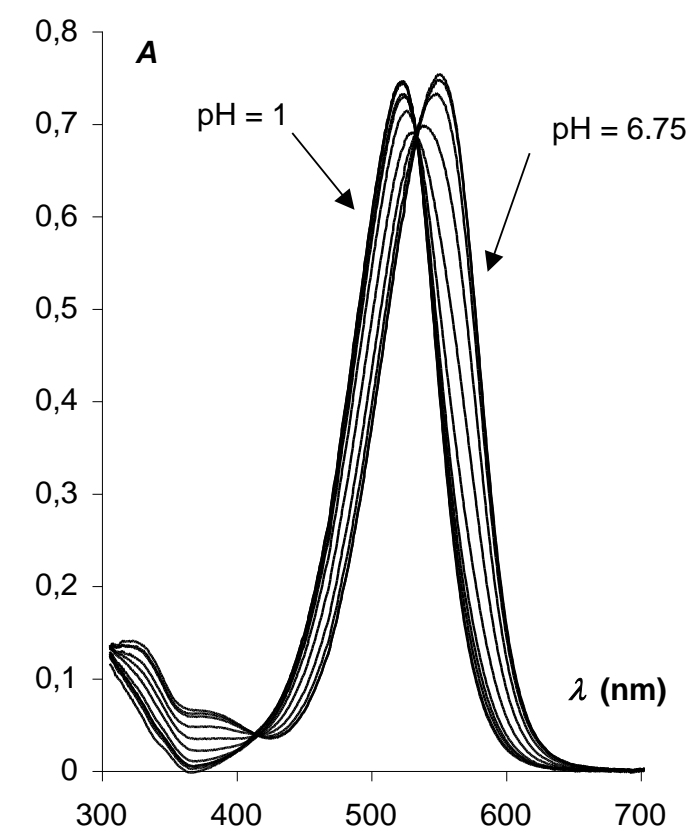


Figure 2

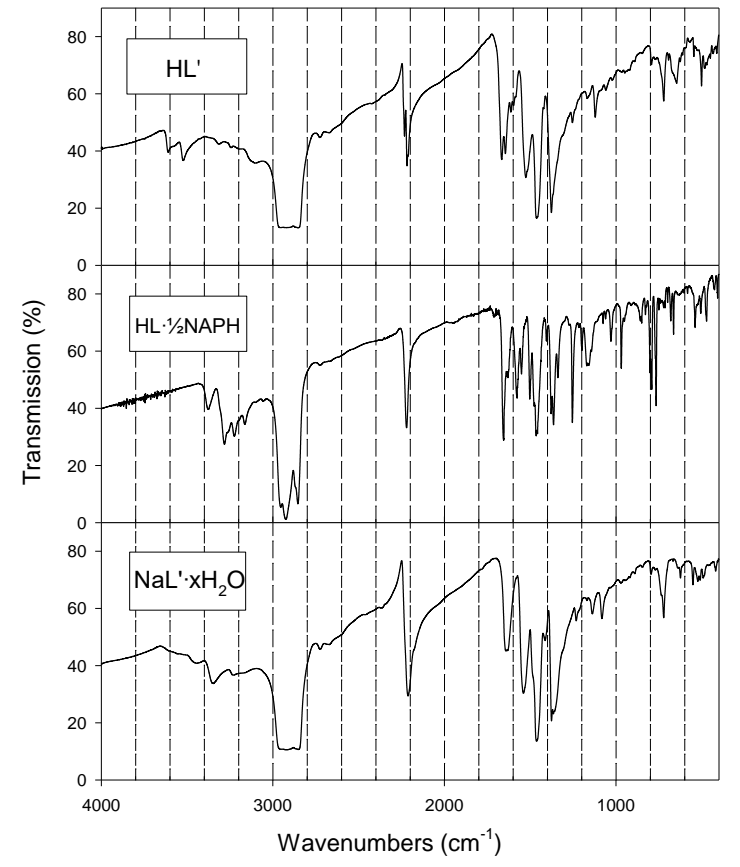


Figure 3

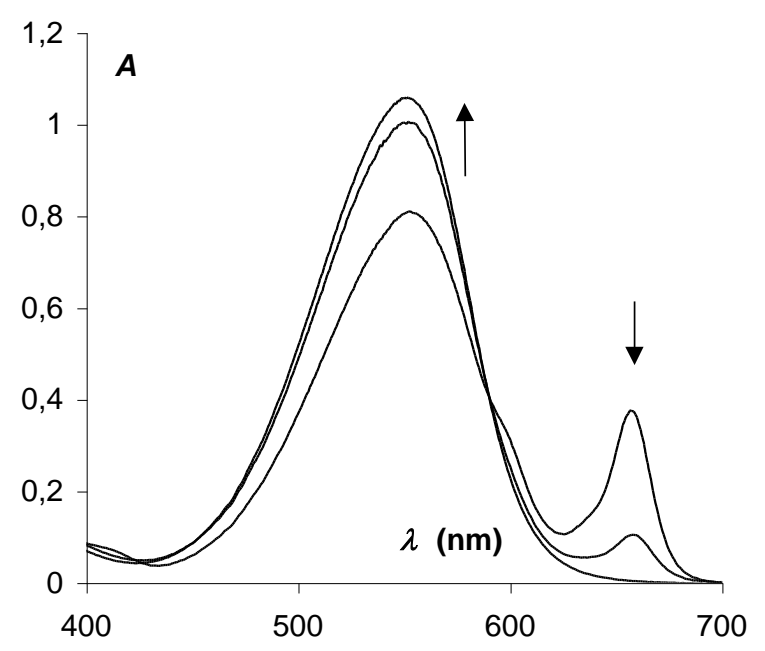


Figure 4

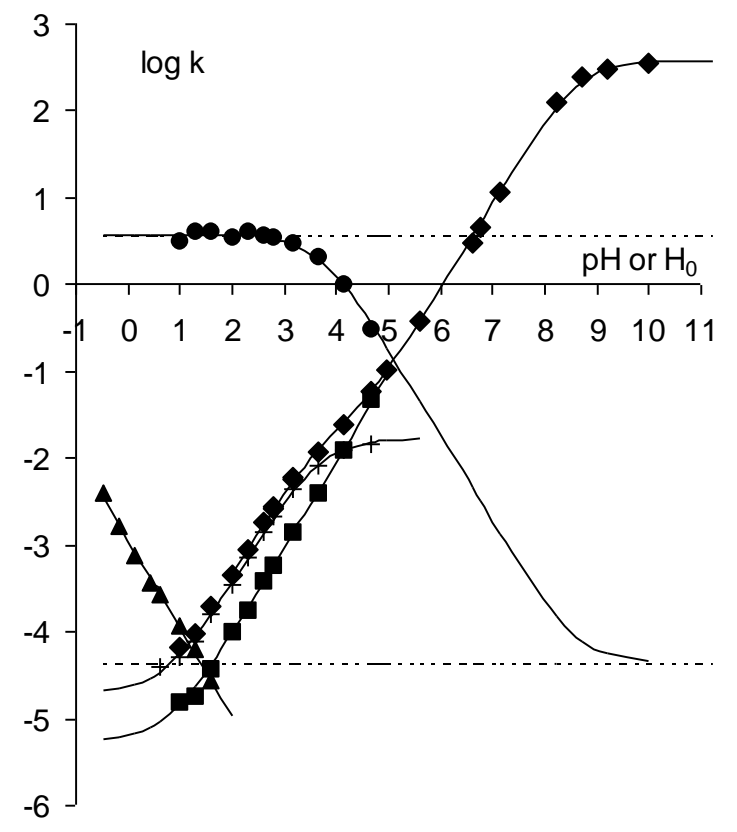


Figure 5

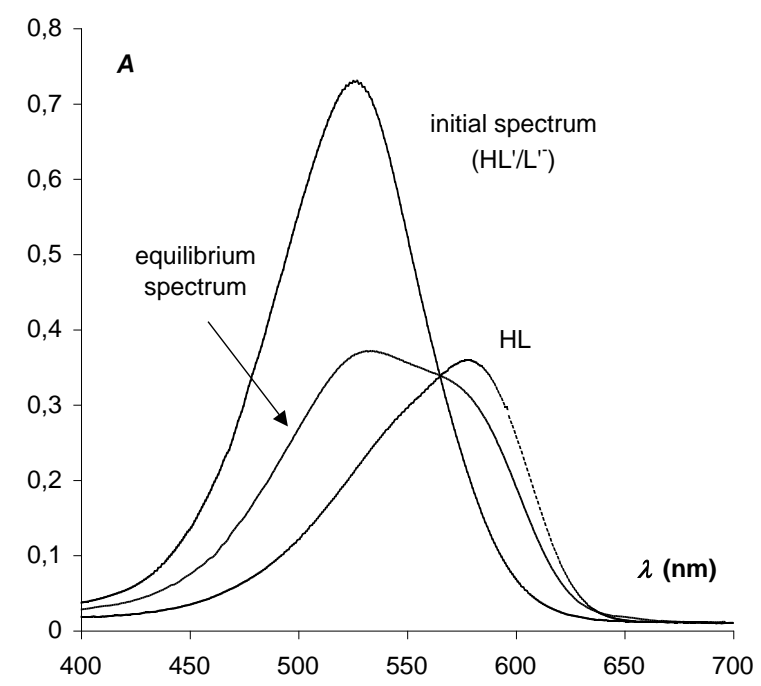


Figure 6

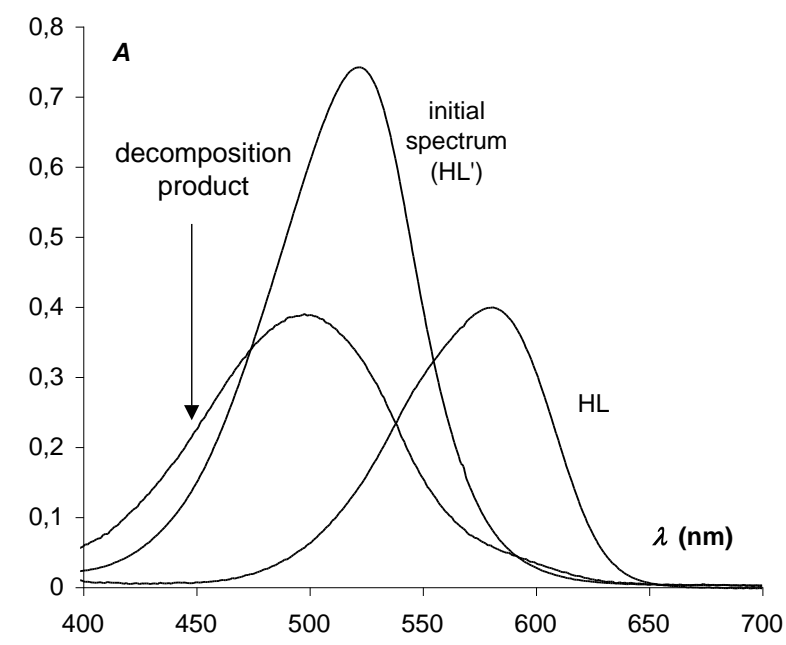


Figure 7
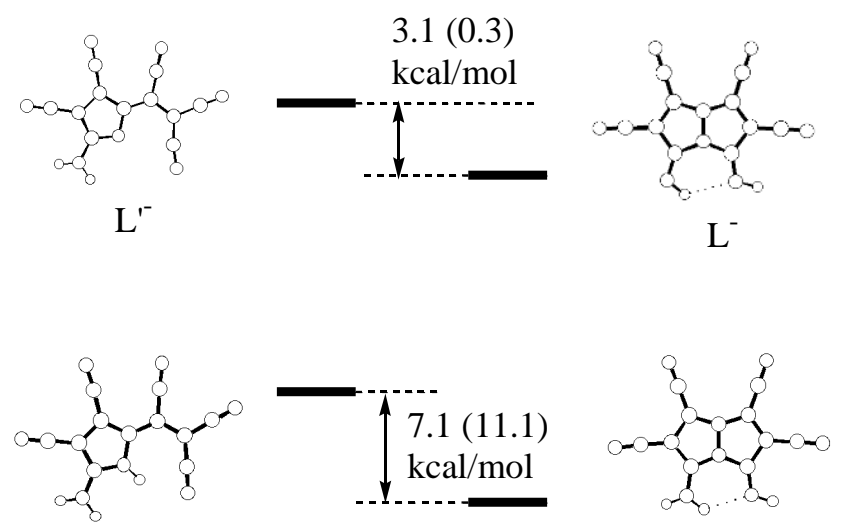

HL'

HL 
Figure 8

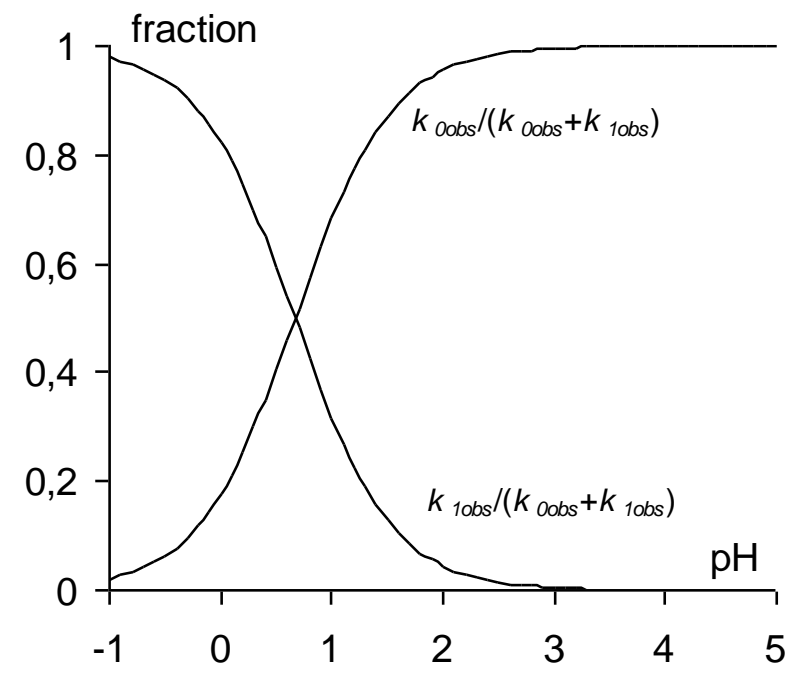


Figure 9

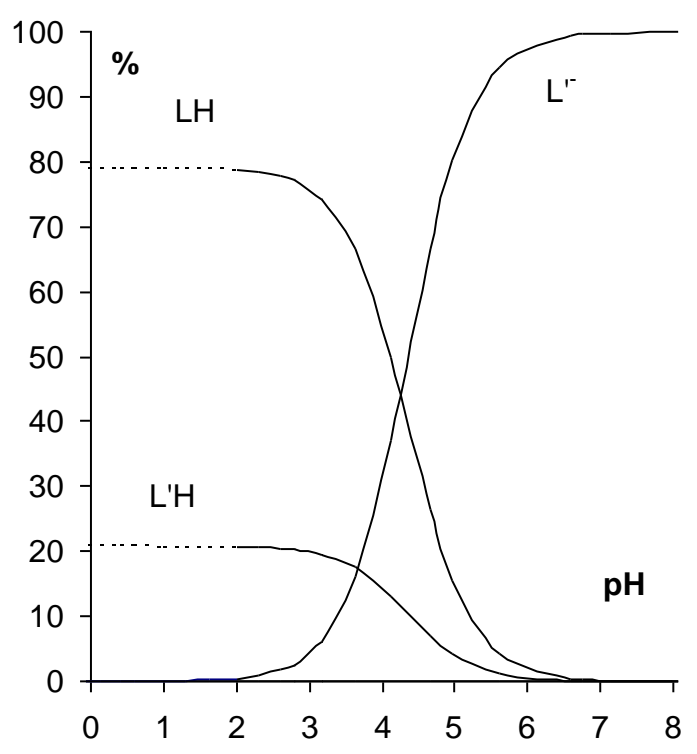




\section{Chart 1}<smiles>N#CC1=C(C#N)c2c(C#N)c(C#N)c(N)n2C1=N</smiles>

HL<smiles>N#CC(C#N)=C(C#N)c1[nH]c(N)c(C#N)c1C#N</smiles>

$\mathrm{L}^{-}$<smiles></smiles>

ML

\section{Chart 2}

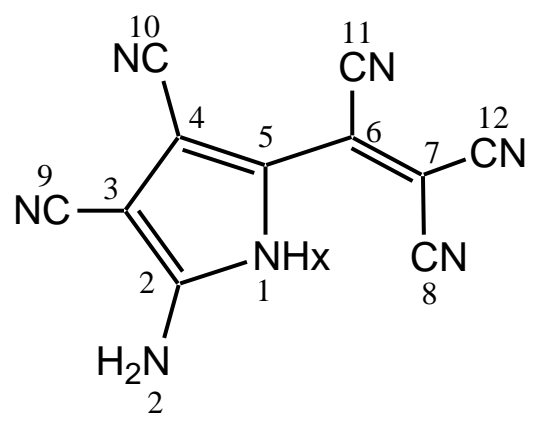

$$
(\mathrm{x}=0,1)
$$

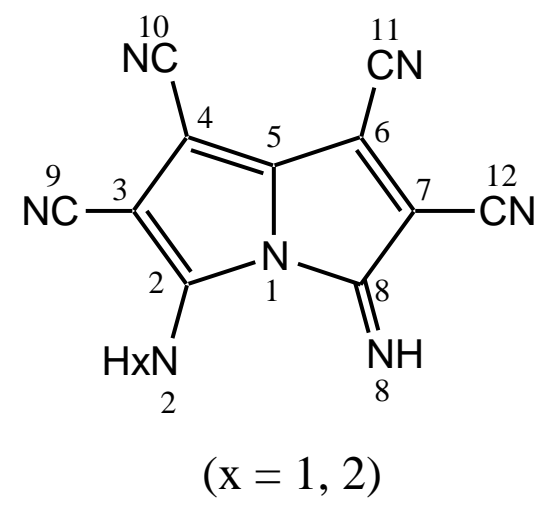


Scheme 1
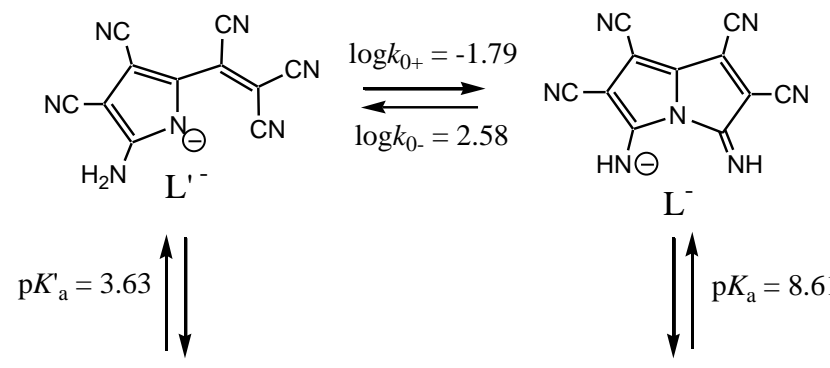

$\downarrow \uparrow \mathrm{p} K_{\mathrm{a}}=8.61$

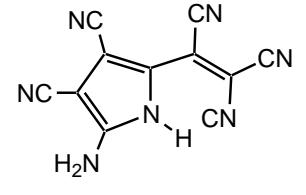

HL'

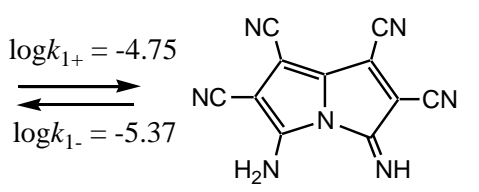

HL

Scheme 2

$$
L \stackrel{k_{\mathrm{i}+}}{\underset{k_{\mathrm{i}}}{\rightleftharpoons} L} L \begin{aligned}
& k_{\mathrm{iobs}}=k_{\mathrm{i}+}+k_{\mathrm{i}-} \\
& K_{\mathrm{i}}=\frac{k_{\mathrm{i}+}}{k_{\mathrm{i}-}}=\frac{[L]_{\mathrm{eq}}}{\left[L^{\prime}\right]_{\mathrm{eq}}}
\end{aligned}
$$

Scheme 3

$$
\begin{aligned}
\mathrm{HL} \stackrel{K_{\mathrm{a} 2}}{\rightleftarrows} \mathrm{H}_{2} \mathrm{~L}^{+} \\
\mathrm{H}_{2} \mathrm{~L}^{+} \stackrel{k_{2}}{\longrightarrow} \text { decomposition }
\end{aligned}
$$

rate $=k_{\mathrm{d}}[\mathrm{HL}]=\left(k_{2} / K_{\mathrm{a} 2}\right)\left[\mathrm{H}^{+}\right][\mathrm{HL}]$ 